\title{
Locomotion Produced in Mesencephalic Cats by Injections of Putative Transmitter Substances and Antagonists into the Medial Reticular Formation and the Pontomedullary Locomotor Strip
}

\author{
B. R. Noga, J. Kettler, and L. M. Jordan \\ Department of Physiology, Faculty of Medicine, University of Manitoba, Winnipeg, Canada R3E OW3
}

The purpose of this study was to determine the distribution of cells in the medial reticular formation (MRF) and the pontomedullary locomotor strip (PLS), which can induce locomotion when activated. Controlled microinjections of neuroactive substances (Goodchild et al., 1982) into the MRF or PLS were made in order to activate cell bodies in those areas. The ability of trigeminal receptive field stimulation to induce locomotion before and after drug infusion into the PLS was also assessed since the PLS and the spinal nucleus of the trigeminal nerve are similar in their anatomical distribution. Experiments were performed on precollicular-postmamillary decerebrate cats walking on a treadmill.

Injections of glutamic acid (GA; $500 \mathrm{nmol}$ ) into the MRF produced locomotion that was antagonized by infusion of glutamic acid diethyl ester into the same spot. Decreases in the current threshold for locomotion produced by electrical stimulation of the MRF were observed when the MRF was infused with either GA (40-80 nmol), DL-homocysteic acid (DL-HCA; $200 \mathrm{nmol}$ ), or picrotoxin (PIC; $15 \mathrm{nmol}$ ). Injections of GA (100 nmol), DL-HCA (700 nmol), PIC (10-50 nmol), and substance $P$ ( 2 nmol) into the PLS also produced locomotion. Locomotion produced by injections of PIC into the PLS was blocked by infusion of equal amounts of muscimol or GABA. Effective PLS injection sites were all confined to the trigeminal spinal nucleus or immediately ventral and medial to this in the adjacent lateral reticular formation. Trigeminal nerve peripheral field stimulation evoked locomotion after microinjection of PIC into the PLS, although this same facial stimulus was not effective prior to drug injection.

We conclude that the MRF and PLS regions of the cat brain stem contain cells that produce locomotion when chemically stimulated, and we suggest that the PLS is closely related to or synonymous with the spinal nucleus of the trigeminal nerve. Furthermore, we suggest that stimulation of trigeminal afferents is analogous to stimulation of segmental afferent pathways in the production of locomotion (Sherrington, 1910; Jankowska et al., 1967; Afelt, 1970; Budakova, 1972; Grillner and Zangger, 1979).

\footnotetext{
Received May 22, 1987; revised Oct. 26, 1987; accepted Nov. 3, 1987.

We would like to thank S. Nault for technical assistance and R. Brownstone D. Kriellaars, D. A. McCrea, and S. Shefchyk for their helpful comments. This research was supported by a Medical Research Council of Canada (MRC) Grant to L.M.J.

Correspondence should be addressed to L. M. Jordan at the above address.

Copyright (C) 1988 Society for Neuroscience $0270-6474 / 88 / 062074-13 \$ 02.00 / 0$
}

Stimulation of the classical mesencephalic locomotor region (cuneiform nucleus), or MLR (Shik et al., 1967), of the midbrain (P2, L4, H-1) produces locomotion in decerebrate cats placed on a treadmill. Descending fibers from this site terminate in the gigantocellular (FTG) and magnocellular(FTM) tegmental fields of the medial pontomedullary reticular formation (MRF) and do not project directly to the spinal cord (Steeves and Jordan, 1984). As summarized by Jordan (1986), reticulospinal cells in the MRF then produce locomotion by pathways traveling in the ventral lateral funiculus (VLF) of the spinal cord. Electrical stimulation of the MRF can produce locomotion (Mori et al., 1978, 1980; Garcia-Rill and Skinner, 1987), and cells in this region show increased metabolic activity during MLR-evoked fictive locomotion (Kettler and Jordan, 1984). The direct evidence implicating the involvement of cells in the MRF in the mediation of locomotion includes the observation that cooling restricted areas in the MRF to block synaptic transmission can reversibly abolish both spontaneous and MLR-evoked locomotion (Shefchyk et al., 1984) and the finding that injections of cholinergic agonists or substance $P$ into the MRF can elicit locomotion (Garcia-Rill and Skinner, 1987). However, the involvement of other putative neurotransmitters in the locomotion produced by activation of the MLR is indicated by a number of recent findings. Cholinergic activation is clearly not required for initiation of locomotion because cholinergic antagonists do not block the initiation of locomotion from the classical MLR (Noga et al., 1987). Furthermore, very few ACh (Lee et al., 1986) or substance P-containing cells (Léger et al., 1983) are found within the region of the classical MLR.

A site medial (P2, L2.7, H-0.5) to the classical MLR that includes the mesencephalic nucleus of the fifth cranial nerve and the periaqueductal gray has also been shown to produce locomotion when electrically stimulated (Garcia-Rill et al., 1983; Shefchyk et al., 1984). This site, referred to as the "medial MLR," may produce locomotion by a pathway that travels through the area known as the pontomedullary locomotor strip (PLS) (Garcia-Rill et al., 1983; Shefchyk et al., 1984). The PLS extends throughout the lateral tegmentum of the brain-stem medial and ventral to the spinal nucleus of the fifth nerve (Mori et al., 1977; Shik and Yagodnitsyn, 1977, 1978) and continues in the spinal cord in the dorsolateral funiculus (DLF) (Kazennikov et al., 1980, 1983a, b). It has been suggested that this lateral tegmental locomotor region is a polysynaptic pathway (Mori et al., 1977; Shik and Yagodnitsyn, 1978) with the cells of origin (the pontomedullary locomotor column) located medial and ventral to its axonal tract, the PLS (Selionov and Shik, 
1984). Others (Garcia-Rill et al., 1983) have claimed that the PLS corresponds to Probst's tract, a fiber pathway descending from the mesencephalic nucleus of the trigeminal nerve (Corbin, 1942). The only direct evidence suggesting that cell bodies in the PLS region are involved in the production of locomotion comes from the observation that cooling of the PLS region to temperatures that abolish synaptic transmission reversibly abolishes locomotion elicited by stimulation of the medial MLR (Shefchyk et al., 1984).

In order to confirm the presence of neuron somata in the MRF and PLS which can produce locomotion when stimulated and to map their distribution in the brain stem, we adapted a technique for the selective activation of cell bodies by the localized injcction of small quantitics of putative neurotransmitters (Goodchild et al., 1982). In this paper we demonstrate that the selective activation of cell bodies in both the MRF and the PLS by a variety of neuroactive substances is effective in the initiation of locomotion in the precollicular, postmamillary decerebrate cat.

Although the neural elements comprising the PLS have not been defined, the effective stimulus sites are always in close proximity to the trigeminal spinal nucleus (Shik and Yagodnitsyn, 1977; Garcia-Rill et al., 1983). While there is evidence available that shows that peripheral stimuli within the trigeminal receptive field can induce locomotion (Aoki and Mori, 1981), no studies have been carried out to distinguish between PLS structures and the brain-stem trigeminal nuclei. In this paper, we demonstrate that the PLS is coextensive with the spinal nucleus of the trigeminal nerve and suggest that the production of locomotion by stimulation of the PLS or trigeminal afferents may be analogous to the locomotion initiated by stimulation of segmental afferents (Sherrington, 1910; Jankowska et al., 1967; Afelt, 1970; Budakova, 1972; Grillner and Zangger, 1979). Preliminary results of this paper have been reported elsewhere (Noga et al., 1984).

\section{Materials and Methods}

The experiments were carried out on 32 adult cats weighing $2.0-4.0 \mathrm{~kg}$. Animals were initially anesthetized with a mixture of nitrous oxide and halothane. The trachea was intubated, the left common carotid was cannulated, and blood pressure was monitored with a pressure transducer. Each animal was given $4 \mathrm{mg}$ of dexamethasone (Hexadrol phosphate, Organon) intravenously to reduce tissue swelling. The head of each animal was fixed in a stereotaxic headframe with all 4 limbs free to step on a treadmill belt. The hindquarters were suspended by a sling under the abdomen or by pins attached to the iliac crests. The animals were decerebrated with a precollicular-postmamillary transection of the brain stem, and the anesthesia was subsequently terminated. All wound margins were anesthetized with topically applied xylocaine ointment or by small injections of xylocaine hydrochloride.

An assembly consisting of an insulated monopolar stimulating electrode (tip diameter, $0.1 \mathrm{~mm} ; 0.25 \mathrm{~mm}$ exposed tip length) glued alongside a 30 gauge cannula was used for electrical stimulation and drug injection. After removal of the cerebral cortices for decerebration, the junction of the superior and inferior colliculi (APO), the obex (P14), and the midline (L0) were visualized (coordinates from Berman, 1968). The electrode-cannula assembly was lowered through the cerebellum and stereotaxically positioned in the brain stem. A region extending from P3-P14 and L0-6 was stimulated at all depths (square wave pulse, $0.5 \mathrm{msec}$ duration, $20-30 \mathrm{~Hz}, 10-275 \mu \mathrm{A}$ ) to induce locomotion on the treadmill. The treadmill belt was maintained at a constant speed of 0.4 $\mathrm{m} / \mathrm{sec}$. In this paper we consider a "locomotor movement" to be any limb movement that shows a rhythmical alternation between flexion and extension resulting in a characteristic swing and stance phase of the limb on the treadmill. Any limb that illustrates this type of movement is considered to be in the process of locomotion regardless of the presence of locomotor activity in any other limb. Locomotion was scored as quadrupedal, bipedal, and so forth on the basis of visual observations using this criterion. Locomotion was monitored in all 4 limbs by using clcctromyographic (EMG) electrodes placed into the following muscles: biceps brachii $(\mathrm{BB})$, triceps brachii (TB), tibialis anterior (TA), and lateral gastrocnemius (LG). The EMGs were amplified and recorded on analog magnetic tape (bandpass, $10 \mathrm{~Hz}-2.25 \mathrm{kHz}$ ) for later analysis.

Drugs were infused in those sites where electrical stimulation could produce locomotion consistently. The various drugs dissolved in $0.9 \%$ saline and maintained at pH 7.2-7.5 included GABA $(0.005-0.01 \mathrm{M})$, muscimol (MUS; 0.005-0.01 M), picrotoxin (PIC; 0.005-0.01 M), DLhomocysteic acid (DL-HCA; $0.1 \mathrm{M}$ ), L-glutamic acid (GA; 0.005-0.1 $\mathrm{M})$, glutamic acid diethyl ester (GDEE; 0.005-0.1 M), and substance $P$ (SP; $0.74 \mathrm{~mm}$ ). Concentration ranges were chosen on the basis of previous successful experiments using drug injections for the initiation of locomotion (Garcia-Rill et al., 1985). The excitatory compounds DLHCA and GA, were infused on the assumption that they would produce effects similar to those seen with electrical stimulation, since iontophoresis of these compounds is known to excite cells in both the MRF and PLS regions (Tébecis, 1973; Henry et al., 1977; Greene and Carpenter, 1985). SP has been shown to excite cells within the region of the PLS (Henry et al., 1977) and to induce locomotion after injection into either the MRF or MLR (Garcia-Rill and Skinner, 1987). PIC was used because it has been shown to be effective in inducing locomotion after infusion into the MLR (Garcia-Rill et al., 1985). GABA and MUS were used to reverse the actions of PIC, while GDEE was used to antagonize the action of GA. The electrode and cannula assembly was removed and rinsed thoroughly with saline between applications of drugs. Drugs were usually infused at a rate of $1 \mu \mathrm{l} / \mathrm{min}$ for $1-5$ minutes. Flow was controlled by a model 341 syringe pump (Sage Instruments) with a Hamilton 10 or $50 \mu \mathrm{l}$ syringe attached to the cannula by PE 60 polyethylene tubing. Control injections of $0.9 \% \mathrm{NaCl}$ at similar infusion parameters were also given in some sites.

In some experiments, drugs were infused into sites $1.5 \mathrm{~mm}$ lateral or medial to sites producing locomotion with electrical stimulation in order to evaluate the extent of drug diffusion to surrounding tissue. An assessment of drug spread could only be made if locomotion could be produced by a subsequent injection of the same into the adjacent "locomotor" region. In other experiments $(n=5)$, attempts were made to induce treadmill locomotion before and after drug infusion by stimulation of various parts of the face, neck, and chest regions by gentle or brisk rubbing or pinching or with a calibrated mechanical stimulus (Rowan aesthesiometer RA-100).

The locations of effective stimulus and/or infusion sites were determined at the end of each experiment. In most cases, sites were marked electrolytically $(2-5 \mathrm{~m} \Lambda, 3 \mathrm{sec})$ or with a dye injection of $1 \%$ Procion rubine or $10 \%$ Fast green at volumes equal to the drug injection. The locations of effective sites within the brain stem were also estimated stereotaxically after removal of the cerebellum by repositioning the electrodes and noting the depth of the electrode with respect to the floor of the IVth ventricle. At the end of most experiments, the brain stem was removed and placed in Lillies' neutral buffered formalin overnight. Frozen sections $(30 \mu \mathrm{m})$ were cut and stained according to the method of Klüver and Barrera (1953).

Ten second periods of full-wave rectified and low-pass filtered EMG signals were analyzed with a Hewlett-Packard 9836 computer at the end of each experiment. The EMG linear envelope signals from all muscles were digitized at $100 \mathrm{~Hz}$ and the data stored on floppy disk. The signals were then plotted for visual inspection.

\section{Results}

\section{Electrically induced locomotion}

Treadmill locomotion could be produced by electrical stimulation $(25-225 \mu \mathrm{A})$ of the medial pontomedullary reticular formation and the pontomedullary locomotor strip (Figs. 1, 2). The region of the MRF that was capable of electrically induced locomotion extended from $\mathrm{P} 4$ to $\mathrm{P} 14$ and $\mathrm{L} 0$ to $\mathrm{L} 2$ and included the FTG, FTM, inferior central raphe nucleus (CI), and postpyramidal nucleus of the raphe (PPR) (Fig. 2). This region is more extensive than the $\mathrm{P} 3-\mathrm{P} 9 \mathrm{MRF}$ regions previously shown to be capable of producing locomotion when electrically stimulated (Mori et al., 1978, 1980). The effective PLS sites included the lateral tegmental field (FTL) medial and ventral to the spinal 
Figure 1. A, Schematic drawing of the brain-stem surface (P3-P15, L0-L7; cerebellum excluded for illustrative purposes) from the area indicated in the inset to demonstrate the rostrocaudal and mediolateral distribution of sites capable of producing locomotion when electrically stimulated. All electrode tracts are from animals that could locomote with PLS and MRF stimulation. Numbers of trials are indicated by relative size of each circle. Limbs used during locomotion are indicated by the shaded quadrant within each circle; open circles represent areas ineffective in inducing locomotion when stimulated. $B$, Histograms indicating the distribution of locomotor (shaded) and nonlocomotor (open) trials at different brain-stem $P$ levels ( $X$ axis: laterality; $Y$ axis: number of trials).

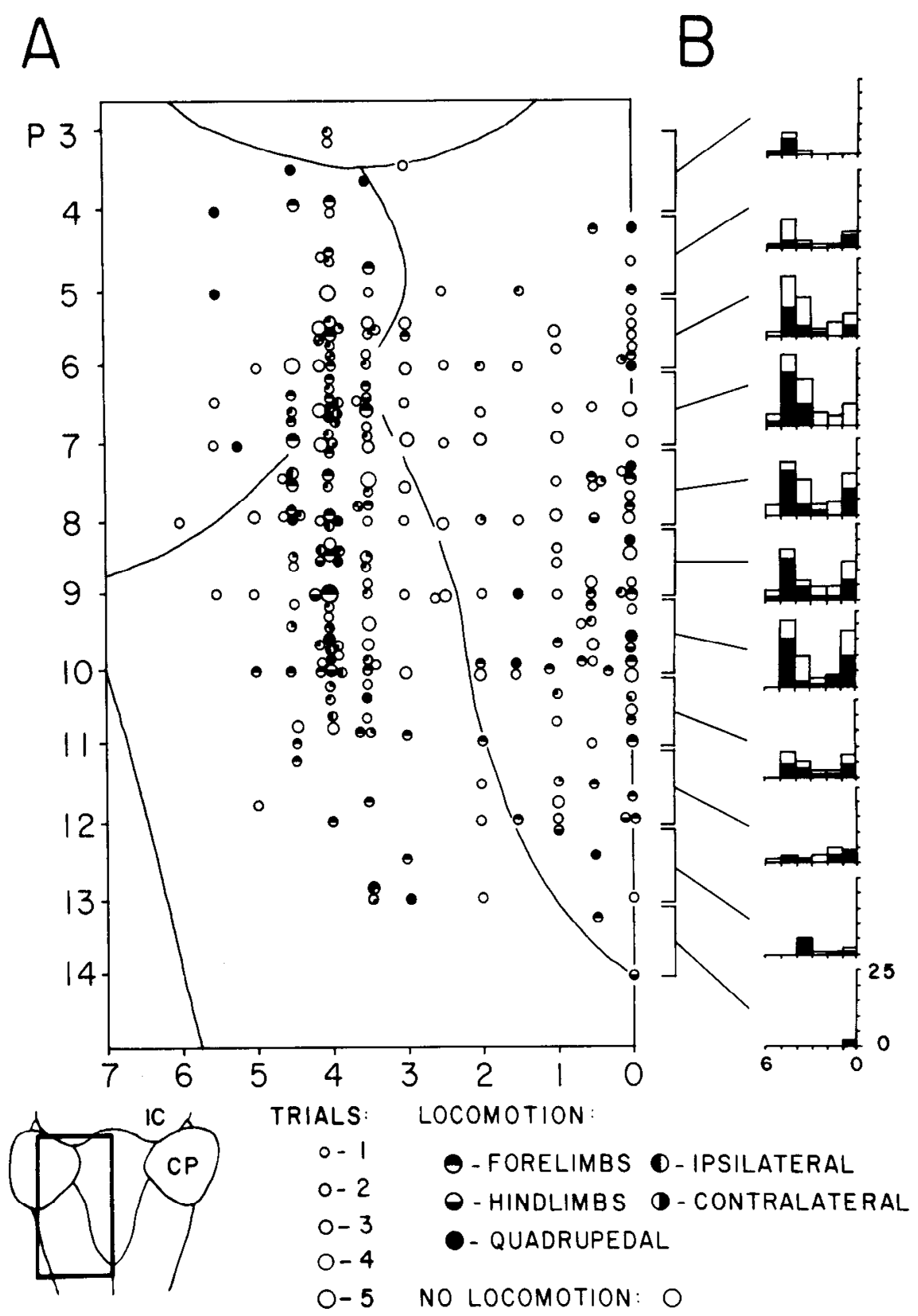

nucleus of the fifth nerve as previously described (Mori et al., 1977; Shik and Yagodnitsyn, 1977) but also included the spinal nucleus of the fifth nerve (5SM, 5SP). These effects were obtained in trials throughout the longitudinal extent of the brain stem from P3 to P13.

The brain-stem sites where treadmill locomotion was produced by electrical stimulation are illustrated in Figure $1 B$. The MRF and PLS are separated by areas that were relatively ineffective for producing locomotion. Stimulation of the region bounded by L3.5-5.5 (PLS) produced locomotion in $62 \%(n=$ 184) of the trials, while stimulation of the region bounded by L0-1.5 (MRF) was effective in $49 \%$ of trials $(n=103)$. In contrast, stimulation of the area between these 2 regions (L2.0-3.0) evoked locomotion in only $17 \%$ of trials $(n=41)$.

The locomotion produced by stimulation of the MRF and PLS was often preceded by increased extensor tonus of the limbs, whereas stimulation of areas $1-2 \mathrm{~mm}$ dorsal to the effective
MRF sites often decreased extensor tonus as described by Mori et al. (1982). Extensor tonus was not evaluated systematically in the present study, however. A significantly higher $(p<0.001$, Student's $t$ test) threshold for electrically induced locomotion was observed for the MRF (mean $=145.0 \pm 3.7 \mu \mathrm{A}$ ) as compared with the PLS $(95.1 \pm 43.7 \mu \mathrm{A})$.

Stimulation of the MRF or PLS produced quadrupedal locomotion in $13.5 \%$ of the trials. However, other stepping patterns during locomotion were also observed (Fig. 1A), including bilateral forelimb $(47.4 \%)$, ipsilateral (with reference to site of stimulation) forelimb (14.6\%), contralateral forelimb $(5.9 \%)$, bilateral hindlimb $(7.0 \%)$, ipsilateral hindlimb $(1.8 \%)$, contralatcral hindlimb $(0.6 \%)$, ipsilateral fore- and hindlimb $(4.7 \%)$, and bilateral forelimb and ipsilateral hindlimb (2.3\%). The remaining $2.2 \%$ displayed various combinations of the above categories. A somatotopic organization was not apparent when data from all animals were grouped together: Stimulation of a similar 

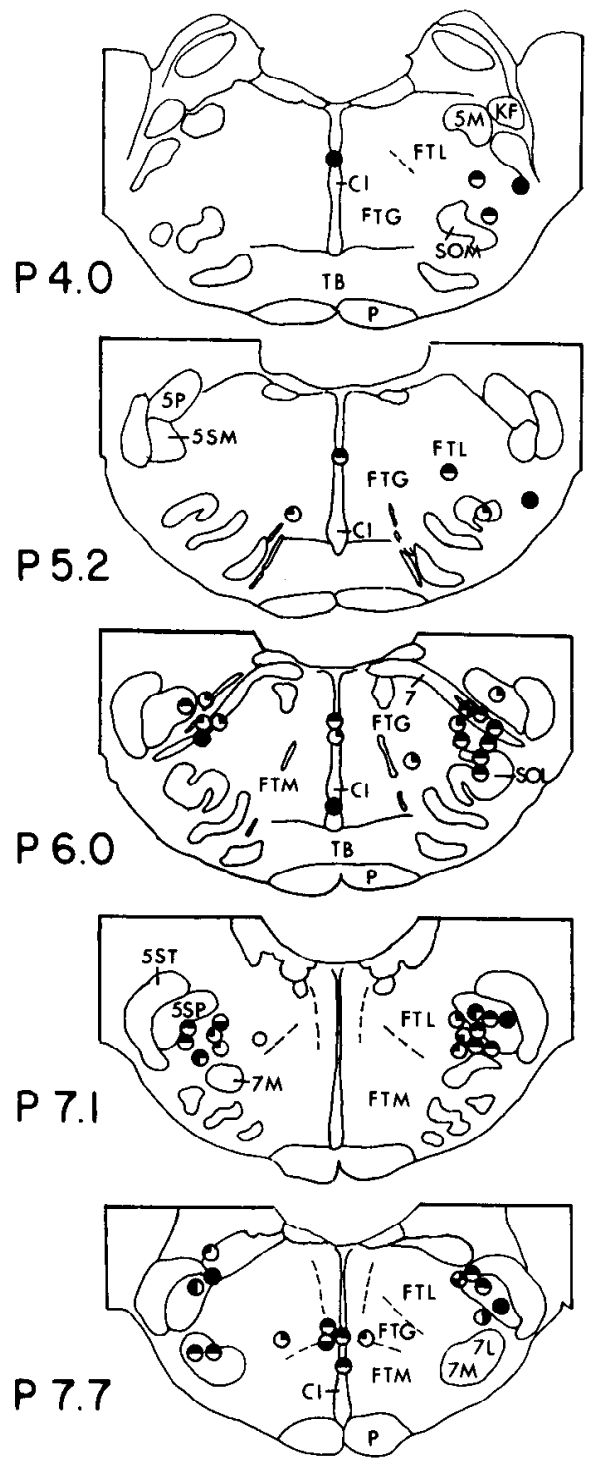
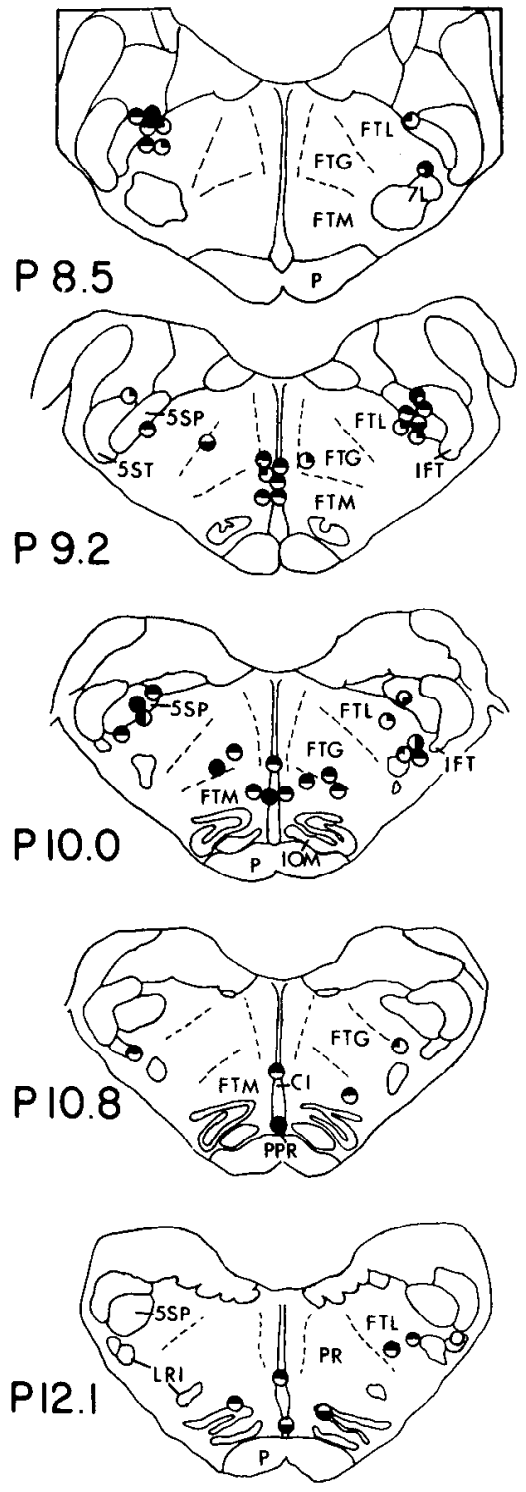

Figure 2. Distribution of sites within the brain stem that produce locomotion when electrically stimulated. Two general areas are indicated. MRF sites are found in the raphe nuclei or adjacent magnocellular or gigantocellular tegmental fields ( $F T M$ or $F T G$ ). At more rostral levels, the effective sites are located more dorsally. Effective sites corresponding to the PLS are found within the spinal nucleus of the fifth nerve $(5 S P)$ or medial and/or ventral to it in the lateral tegmental field $(F T L)$. Symbols indicating limb involvement during locomotion are as illustrated in Figure 1 except that right and left quadrants indicate right and left sides, respectively. site in different animals could produce different stepping patterns during locomotion. However, within the same animal slightly different stepping patterns could be seen with stimulation of adjacent areas within the brain stem.

\section{Drug-induced locomotion}

Drug infusions were made in sites that could reproducibly elicit locomotion with electrical stimulation. Control saline injections in the MRF and PLS at all rates used for test drug infusions did not produce any observable changes in EMG activity or influence the threshold for electrically induced locomotion.

\section{Extent of drug diffusion}

To estimate the extent of drug diffusion with injections into the brain stem, Procion rubine (1\%) and Fast green $(10 \%)$ were infused in volumes similar to the drug infusion trials. Infusions of 3 and $5 \mu$ of Procion rubine produced detectable spread (total diameter) of $0.5-1$ and 1-2 $\mathrm{mm}$, respectively. Infusions of 1 and $3 \mu \mathrm{l}$ of Fast green produced spread of 1 and $2 \mathrm{~mm}$ (total diameter), respectively. With both dyes an additional $0.5 \mathrm{~mm}$ vertical spread (along the cannula tract) was also observed. Ad- ditional experiments were conducted to determine whether the diffusion pattern of PIC was comparable to that seen after injections of similar quantities of Procion rubine or Fast green. A site where electrical stimulation did not produce locomotion, $1.5 \mathrm{~mm}$ medial or lateral to a PLS site (see Fig. 6: P7.1 and P12.1), was infused with $3 \mu \mathrm{l}(15 \mathrm{nmol}, 0.005 \mathrm{M})$ PIC. No locomotion was observed after $30 \mathrm{~min}$ of the PIC injection. In addition, no change was observed in the threshold for electrically induced locomotion produced by stimulation of the PLS site. Subsequent infusion into the PLS site, however, lowered the threshold for electrically induced locomotion in one case and produced locomotion by itself in the other (Fig. 7). This indicates that for injections of $3 \mu \mathrm{l}$ PIC, drug diffusion was on the order of $\leq 1.5 \mathrm{~mm}$ (total diameter) and thus comparable to the diffusion pattern observed with infusions of $3 \mu$ l Procion rubine or $1 \mu$ l Fast green.

\section{$M R F$ drug infusions}

Infusions of various drugs into the MRF could influence the locomotor capability of the animal by either initiating stepping or by decreasing the threshold for electrically induced loco- 


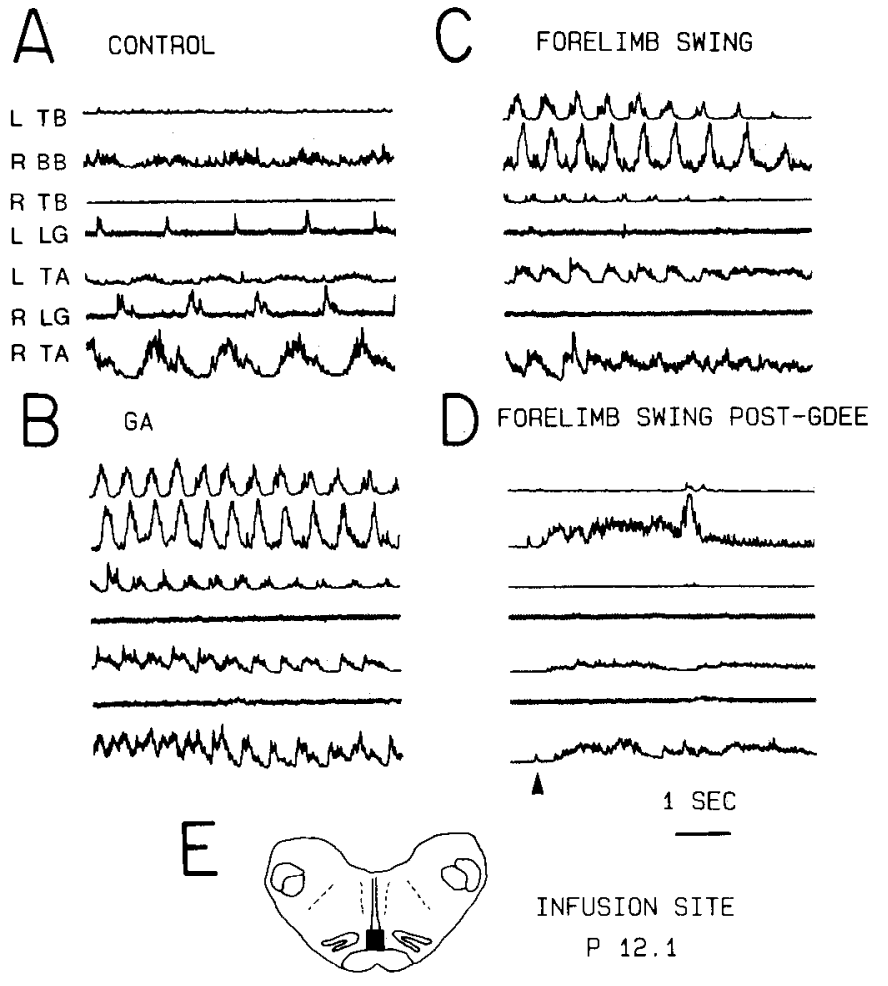

Figure 3. Electrically induced and drug-induced locomotion in the MRF. A, EMG records during quadrupedal locomotion produced by electrical stimulation of the site indicated in $E$. Injection of $500 \mathrm{nmol}$ glutamic acid $(G A)$ (in $5 \mu \mathrm{l}, 0.1 \mathrm{M}$ ) into the MRF also induces coordinated quadrupedal locomotion $(B)$. A change in phasic activity of some muscles is seen during locomotion produced by GA infusion (see text). Bouts of locomotion were induced by swinging the forelimbs $(C)$ during periods of quiescence. $D$, Cessation of walking due to a $500 \mathrm{nmol}$ (in 5 $\mu \mathrm{l}, 0.1 \mathrm{M}$ ) injection of glutamic acid diethyl ester (GDEE) into the same site. Only tonic muscle activity is evident after forelimb swing (arrow). EMG traces in $B-D$ are in same order as listed in $A$.

motion. Glutamic acid was the only compound tested that produced locomotion after infusion into the MRF. Figure 3, $A$ and $B$, illustrates the quadrupedal locomotion produced by electrical stimulation or by injection of $500 \mathrm{nmol} \mathrm{GA}(5 \mu \mathrm{l}, 0.1 \mathrm{M})$ into a midline site (PPR and FTM) $2 \mathrm{~mm}$ rostral to the obex and $3.8 \mathrm{~mm}$ ventral to the floor of the fourth ventricle (Fig. $3 E$ ). Within 17 min of drug infusion the threshold for electrically induced locomotion decreased from 100 to $20 \mu \mathrm{A}$ and muscle tonus increased in forelimb extensors (as determined by passive resistance to limb flexion and EMG activity). Within $30 \mathrm{~min}$ of drug infusion, spontaneous quadrupedal locomotion (Fig. 3B) began in an episodic fashion (1-3 min duration) separated by periods of quiescence $(0.5-2 \mathrm{~min})$. During quiescent periods locomotion could be reestablished by swinging the forelimbs backward and releasing them (Fig. $3 C$ ). Although the fore- and hindlimb flexors (BB, TA) were phasically active during electrical and drug-induced locomotion, the activity of fore- and hindlimb extensors (TB,LG) was different following GA: The right and left TB became phasically active, whereas the phasic activity of the right and left LG ceased. Episodes of drug-induced locomotion continued to occur for $100 \mathrm{~min}$ after the infusion. At this time, infusion of the GA antagonist GDEE (500 nmol in 5 $\mu 1,0.1 \mathrm{M})$ into this site decreased the vigor and duration of the GA-induced locomotion within $3 \mathrm{~min}$, and locomotion completely ceased after $12 \mathrm{~min}$. Forelimb swinging was completely ineffective for initiating locomotion during this period (Fig. 3D). However, the effects of the antagonist were short-lasting, and locomotion began again within $15 \mathrm{~min}$ of the infusion of GDEE.

In a different animal, infusion of $500 \mathrm{nmol} \mathrm{GA}(5 \mu 1,0.1 \mathrm{M})$ into the MRF (P9, LO, H-8.3) produced episodic forelimb locomotion after $8 \mathrm{~min}$ for a period lasting $20 \mathrm{~min}$. Muscles demonstrating phasic activity during the control remained phasic following GA. During GA-induced locomotion, stimuli previously unable to evoke stepping (forelimb swinging and rubbing of the maxillary region of the face) were found to induce locomotion.

Infusions of smaller amounts of GA $(40-80 \mathrm{nmol}$ in $8 \mu \mathrm{l}$, $0.005-0.01 \mathrm{M}$ ) into the MRF of other animals were ineffective in producing locomotion in 6 trials, suggesting a dose-response relationship for the initiation of locomotion by injection of GA into the MRF. A 40-66\% decrease in the threshold for electrically induced locomotion in sites $0.5-1 \mathrm{~mm}$ lateral to the midline (P7.7 and P10.0, Fig. 6) was observed in 2 of these trials.

Infusions of DL-HCA in 2 of 4 trials $(200 \mathrm{nmol}$ in $2 \mu \mathrm{l}, 0.1$ $\mathrm{M})$ and PIC in 3 of 6 trials (15 nmol in $3 \mu \mathrm{l}, 0.005 \mathrm{M})$ also reduced the threshold for electrically induced locomotion by $20-27 \%$ and $53-61 \%$, respectively. Extensor muscle tonus increased following drug infusion, but no stepping movements were produced. After 15-25 min, electrical thresholds began to return to preinfusion values. No effect was observed in the remaining trials even when $300-800 \mathrm{nmol}$ DL-HCA or 25-50 nmol PIC was infused.

Injection sites within the MRF are illustrated in Figures 5 and 6. Effective sites were found from P6 to P12 and LO to L11/2 and within the CI, PPR, FTG, FTM in the ventral half of the brain stem.

\section{PLS drug infusions}

Various compounds were capable of either producing locomotion or decreasing the threshold for electrically induced locomotion after infusion into the PLS. Locomotion was produced by infusions of GA, DL-HCA, PIC, and SP into the PLS. Increased extensor muscle tonus was seen (visual observations) prior to the onset of drug-induced locomotion.

Figure $4 A$ illustrates forelimb locomotion typically produced by electrical stimulation (150 $\mu \mathrm{A})$ of the PLS. Figure $4 B$ illustrates the locomotion produced by infusion of $100 \mathrm{nmol} \mathrm{GA}$ (in $1 \mu \mathrm{l}, 0.1 \mathrm{M}$ ) into the ventromedial aspect of 5SP at P7 (Fig. $4 G$ ) in a different animal. After infusion of $300 \mathrm{nmol}$ into this site, periodic episodes of spontaneous locomotion lasted for 15$20 \mathrm{~min}$. Infusions of $40-80 \mathrm{nmol} \mathrm{GA}$ (in $8 \mu \mathrm{l}$ of $0.005-0.01 \mathrm{~m}$ ) produced $35-67 \%$ decreases in the threshold for electrically induced walking (Fig. 6: P7.7). In one case, the infusion of 40 nmol was sufficient to maintain locomotion for up to $8 \mathrm{sec}$ after the termination of electrical stimulation. In contrast, locomotion stopped upon termination of the electrical stimulus in the control situation. The location of this latter infusion site was within 5SM (Fig. 6: P6.0). In 6 other cases, GA (50-80 nmol) was ineffective other than occasionally increasing the discharge of motor units. In an additional case, infusion of $300 \mathrm{nmol} \mathrm{GA}$ produced convulsive movements but did not induce locomotion.

Infusion of $700 \mathrm{nmol}$ DL-HCA (in $7 \mu \mathrm{l}, 0.1 \mathrm{M}$ ) produced locomotion within $4 \mathrm{~min}$ of injection into a site $4 \mathrm{~mm}$ lateral to the midline (Fig. $4 C$ ), but no accurate depth measurement was obtained for this trial. Injections of smaller quantities (300 nmol in $3 \mu \mathrm{l}, 0.1 \mathrm{M}$ ) in 2 other trials were ineffective. 

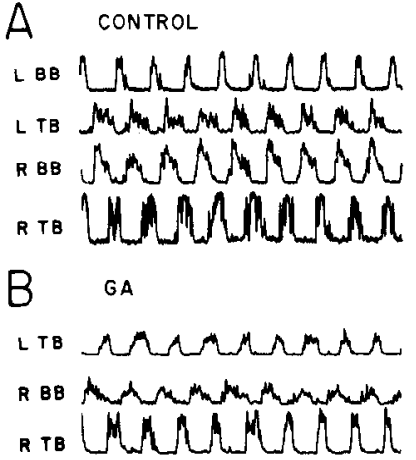

C OL-HCA

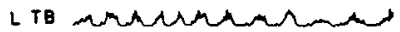

я те YMMMMMMMM

L L WhN Whamant

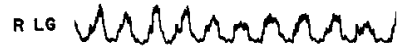
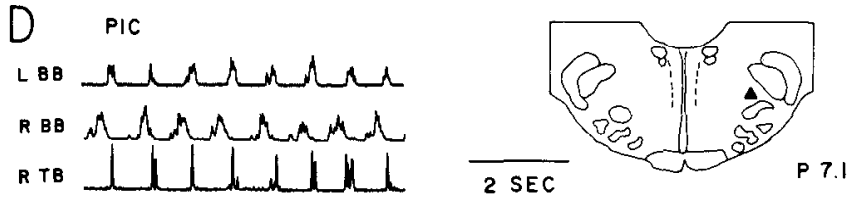

Figure 4. Electrically induced and drug-induced locomotion in the PLS. $A$, Typical EMG records during forelimb locomotion produced by electrical stimulation of the PLS. $B-D$ and $F$, Locomotion produced by injection into the PLS of GA (100 nmol in $1 \mu \mathrm{l}, 0.1 \mathrm{M})$, DL-homocysteic acid (DL-HCA; $700 \mathrm{nmol}$ in $7 \mu \mathrm{l}, 0.1 \mathrm{~m}$ ), PIC ( $25 \mathrm{nmol}$ in $5 \mu \mathrm{l}$, $0.005 \mathrm{M}$ ), and substance $\mathrm{P}$ (SP; $2 \mathrm{nmol}$ in $3 \mu \mathrm{l}, 0.74 \mathrm{mM}$ ), respectively. $E$, Loss of sustained PIC-induced locomotion produced with forelimb swinging following infusion of an equivalent quantity $(25 \mathrm{nmol}$ in $5 \mu \mathrm{l}$, $0.005 \mathrm{M}$ ) of GABA into the same site. $G$. Infusion sites as obtained from electrolytic lesions in the different animals tested. Symbols as in Figure 5 .

Injections of PIC $(0.005-0.0 .1 \mathrm{M})$ into the PLS produced threshold decreases and eventually spontaneous locomotion in 11 trials ( 8 cats). Locomotion could be produced after injection of $10-50 \mathrm{nmol}$ (mean $=30.0 \pm 13.8 \mathrm{nmol})$. The mean infusion volume was $5.5 \pm 2.6 \mu \mathrm{l}$. At high concentrations $(0.01 \mathrm{M})$, a smaller infusion volume was required to produce locomotion, and in one case locomotion was induced before $1 \mu \mathrm{l}(10 \mathrm{nmol})$ had been infused. The threshold for electrically induced locomotion decreased by $24-40 \%$ of the original values in 3 other trials after injection of $15-30 \mathrm{nmol}($ mean $=21.7 \pm 7.6 \mathrm{nmol})$ PIC, but locomotion was not produced by the drug infusion. PIC was without effect in 17 other trials at similar quantities (31.7 $\pm 11.0 \mathrm{nmol}$, range $25-60 \mathrm{nmol})$. Infusions of PIC produced locomotion within $8.4 \pm 7.1$ min (range, 2-20 minutes).

Figure $4 D$ illustrates the spontaneous forelimb locomotion produced after infusion of $25 \mathrm{nmol}$ PIC (in $5 \mu 1,0.005 \mathrm{M}$ ) into the PLS at P6 (Fig. 4G). During the infusion a decrcase (from $150-50 \mu \mathrm{A}$ ) in the threshold for electrical activation of stepping occurred prior to the drug-induced locomotion. The stepping sequences lasted from $10 \mathrm{sec}$ to $1.5 \mathrm{~min}$ and were separated by quiescent periods lasting 1-2 min. This periodic drug-induced locomotion occurred for about $20 \mathrm{~min}$. A second infusion into this site produced an even greater EMG output, but stepping ceased when the animal began to display a tegmental response (Ingram et al., 1932). In other PLS sites, PIC-induced locomotion lasted for periods of up to $60 \mathrm{~min}$ with injections of 15

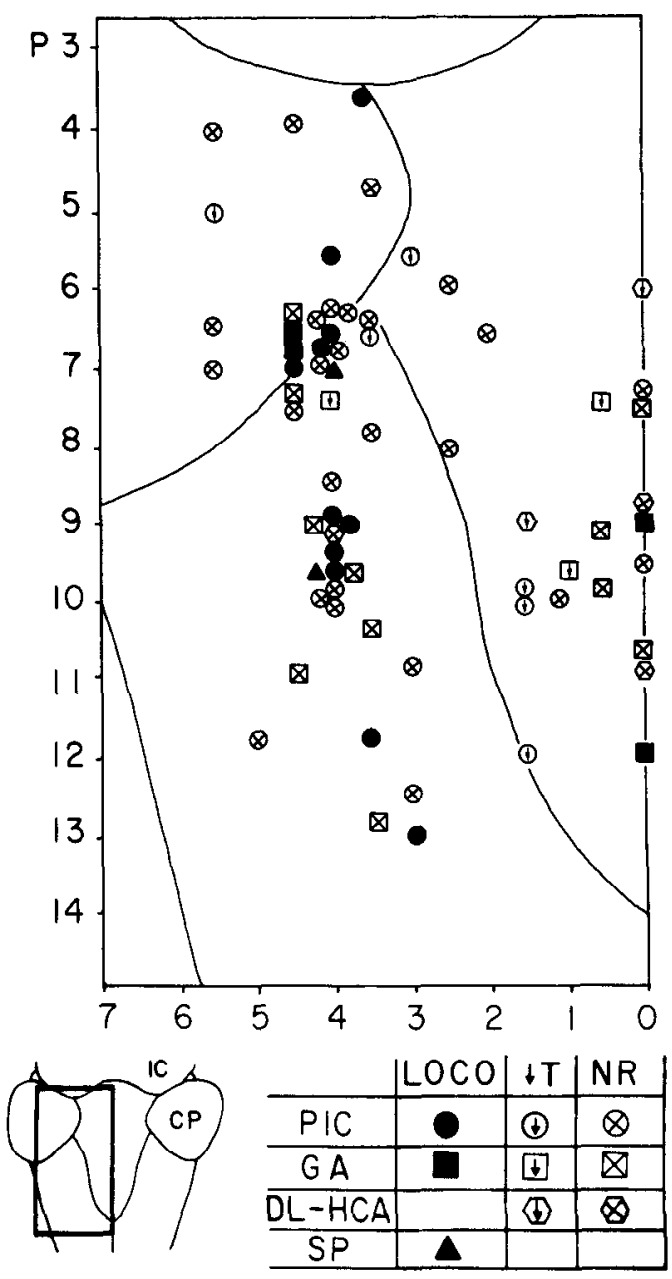

Figure 5. Schematic drawing of the surface of the brain stem from area (P3-P15) indicated in the inset to demonstrate the rostrocaudal and mediolateral distribution of sites capable of producing locomotion after drug infusion. Sites producing decreases in the threshold for electrically induced locomotion or no response $(N R)$ are also indicated. Sites capable of inducing locomotion are found close to the midline and also in the classically defined PLS. Injection sites producing decreased thresholds are found somewhat more lateral to the midline or within the PLS.

nmol (in $3 \mu \mathrm{l}, 0.005 \mathrm{M}$ ) PIC and up to $90 \mathrm{~min}$ with injections of 30 nmol (in $6 \mu 1,0.005 \mathrm{M}$ ). Stepping episodes gradually ceased or were replaced by convulsive movements.

PIC-induced locomotion and electrical stimulation control trials showed the same stepping pattern in $8 / 11$ trials. However, in one experiment, electrically induced quadrupedal locomotion was replaced by ipsilateral fore- and hindlimb locomotion, and in 2 other experiments, bilateral forelimb and contralateral hindlimb locomotion was replaced by forelimb locomotion when PIC was infused. No consistent differences in step cycle rate and the EMG amplitudes during stepping were observed between electrical and PIC-induced locomotion.

The presence or absence of rhythmic EMG activity was assessed from recordings of locomotion produced by electrical stimulation or PIC injection into the PLS. In $65 \%$ of the EMG records, rhythmic activity remained during PIC-induced locomotion. In contrast, loss of activity was observed in $16 \%$ of the recorded muscles, and recruitment of phasic activity occurred in 19\% of the recorded muscles during PIC-induced locomotion. There was no relationship between injection site and the pattern 

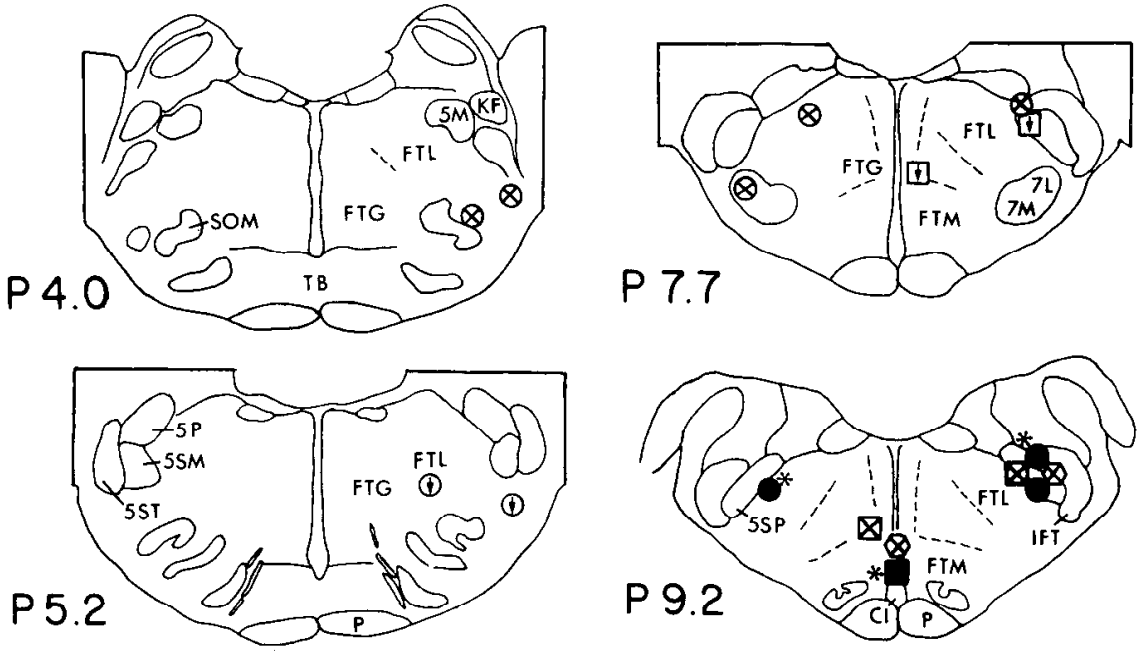

Figure 6. Distribution of drug injection sites at different levels of the brain stem. Areas producing locomotion or decreases in the threshold for electrically induced locomotion following drug infusion are found within the raphe nuclei, FTG, and FTM or within the trigeminal spinal nucleus or adjacent FTL. Ineffective sites are located ventral and medial to the clasically defined PLS. Injection sites producing locomotion with stimulation of the trigeminal receptive field (see text for explanation) are indicated by asterisks. Symbols as in Figure 5 .
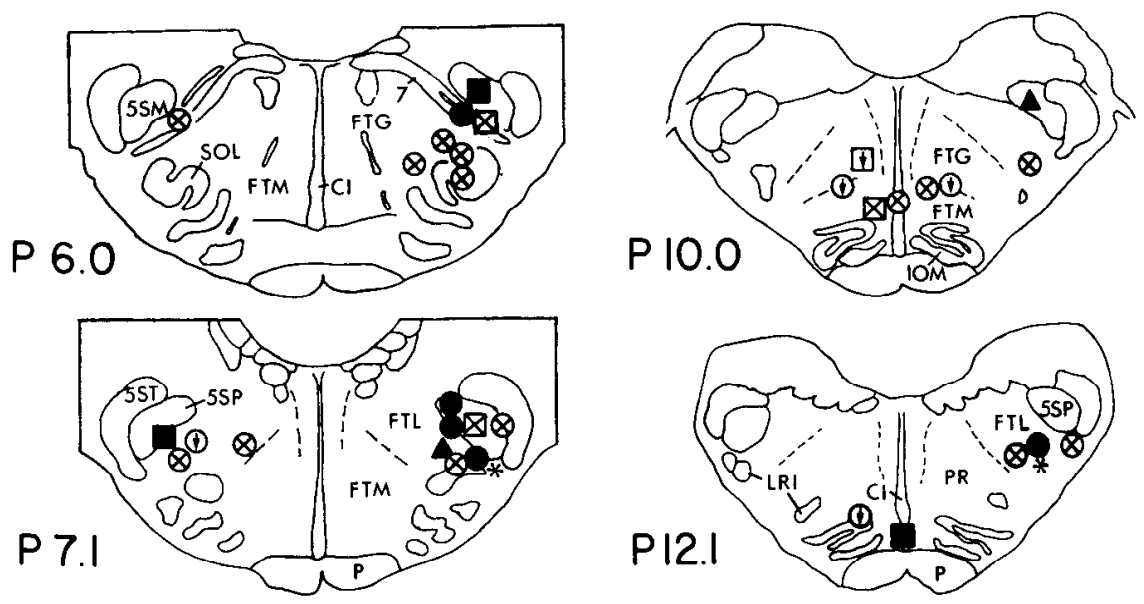

of loss or gain of phasic muscle activity during drug-induced locomotion.

PIC-induced locomotion was antagonized by infusions of either GABA or MUS. Injections of MUS completely and irreversibly blocked PIC-induced locomotion, whereas the effects of GABA were transient. A decrease in the frequency and vigor of PIC-induced locomotion was usually apparent within $5 \mathrm{~min}$ of infusion of an equivalent (nmol) dose of GABA. As illustrated in Figure $4 \mathbb{E}$, locomotion induced by forelimb swinging was reduced to a short stepping sequence ( $2-3$ steps) after infusion of GABA. Within 10-15 min, however, the frequency, length, and intensity of the locomotor episodes gradually approached their original levels.

Injection of $2 \mathrm{nmol} \mathrm{SP}$ (in $3 \mu \mathrm{l}, 0.74 \mathrm{~mm}$ ) into the PLS (Fig. 6) produced locomotion (Fig. 4, F, G), similar to that produced by electrical stimulation of the same site in the 2 animals tested. Periodic episodes of walking were observed shortly after drug infusion (within 1-2 min) and were maintained for periods of up to $30 \mathrm{~min}$. During periods with no spontaneous locomotion, the threshold current for producing locomotion decreased from $60 \mu \mathrm{A}$ (predrug value) to $20 \mu \mathrm{A}$. Unlike the predrug trials, locomotion was also maintained for 5-10 sec after termination of the electrical stimulus.

Injection sites into the PLS are shown in Figures 5 and 6. Injections producing locomotion or decreases in the threshold for electrically induced locomotion were found from P5 to P13 and $\mathrm{L} 3$ to $\mathrm{L} 5$ and within or just ventral and medial to $5 \mathrm{SM}$,
5SP in the adjacent FTL. Most ineffective sites were located ventrally in the FTL.

\section{Trigeminal field-induced locomotion}

Following PIC infusion into the area of the PLS, mechanical stimuli applied to the receptive field of the trigeminal nerve could induce locomotion. Stimulation of the trigeminal field was attempted prior to drug administration. These stimuli never produced locomotion by themselves. Figure 7 shows examples of these effects found after a $15 \mathrm{nmol}$ (in $3 \mu \mathrm{l}, 0.005 \mathrm{M}$ ) injection of PIC in the site illustrated in Figure $7 N$. Stimulation of the trigeminal receptive field ipsilateral to the injection site was more effective for initiating locomotion than stimulation of the contralateral side. Stimuli of greater intensity also produced more vigorous locomotion than did gentle stimuli. Ipsilateral mandibular stimulation (Fig. $7 D$ ) immediately and invariably induced locomotion, whereas a 2 and $5 \mathrm{sec}$ latency period was observed for ipsilateral maxillary and pinna stimulation, respectively (Fig. 7, $E$ and $F$ ). Ipsilateral corneal stimulation (Fig. $7 G$ ) produced locomotion within $2 \mathrm{sec}$ in 1 out of 3 trials, but locomotion was not maintained for the duration of the stimulus. Similarly, jaw opening (Fig. $7 H$ ) produced 4-5 steps in 2 of 6 trials. A longer latency $(7 \mathrm{sec})$ and weaker stepping response was produced with stimulation of the contralateral maxillary region (Fig. 7I). Stimulus sites that failed to produce any locomotion included (as shown in Fig. 7): contralateral pinna (J), contralateral cornea $(\mathrm{K})$, nape of neck $(\mathrm{L})$, chest $(\mathrm{M})$, and perianal 
regions. Infusion sites from 4 other experiments that showed similar locomotion production by trigeminal field stimulation are illustrated by an asterisk in Figure 6 , including a GA infusion site in the MRF. In one experiment (Fig. 6: P9.2, left side) a 14 gm stimulus applied to the ipsilateral pinna induced locomotion but was ineffective when applied to the contralateral pinna. Injection of $15 \mathrm{nmol}$ PIC (in $3 \mu 1,0.005 \mathrm{M}$ ) into a site (which could not produce locomotion when electrically stimulated) 1.5 $\mathrm{mm}$ lateral to the PLS was without effect.

\section{Discussion}

\section{$M L R$-reticulospinal pathway}

The results of this study demonstrate that cell bodies in the pontinc and mcdullary MRF are capable of producing treadmill locomotion. The locations of the cell bodies in the lower brain stem that are capable of initiating locomotion correspond to the MLR fiber terminations reported previously (Steeves and Jordan, 1984) and to the site where cooling to block synapse transmission reversibly abolished locomotion produced by electrical stimulation of the classical MLR (Shefchyk et al., 1984). The present study extends the MRF region previously shown to be capable of generating locomotion when electrically stimulated (Mori et al., 1978, 1980; Garcia-Rill and Skinner, 1987) and shows that an area from the midline to L2 can be stimulated electrically to induce locomotion. This confirms the previous finding by Mori et al. (1978) that midline stimulation is effective for production of locomotion, but it is in contrast to the report by Garcia-Rill and Skinner (1987) who claim that midline stimulation does not produce locomotion. The fact that the electrical threshold for the initiation of locomotion by stimulation of the MRF is higher than that observed for the MLR (Mori et al., 1980) or PLS (this study) suggests that a larger volume of tissue must be stimulated to produce locomotion, possibly due to a more diffuse distribution of neurons within the reticular formation.

These findings support the idea proposed by Orlovsky (1970) that the invariable mediating link for the initiation of locomotion is the reticulospinal system. Lesions in the MRF areas in otherwise intact animals produce profound deficits in posture and locomotion (Zelman et al., 1983). Furthermore, subtotal spinal cord lesion studies have demonstrated that locomotion produced by stimulation of the classical MLR requires the VLF since complete destruction of the alternatively proposed MLRPLS-DLF pathway by simple transection (Steeves and Jordan, 1980 ) or extended dorsal hemisections (Noga et al., 1986) is without effect on MLR-evoked locomotion. As it appears that the excitatory pathway to lumbar motoneurons for the initiation of locomotion may involve at least one synapse at the spinal cord level (Shefchyk and Jordan, 1985), the locomotor effects seen with MRF stimulation would have to be mediated by at least a disynaptic linkage to limb motoneurons. This connectivity has been reported between the MRF and limb motoneurons (Peterson et al., 1979).

The variability in stepping patterns observed with MRF stimulation suggests that there is a somatotopic organization for the initiation of locomotion within the reticular formation. Although no somatotopic organization was apparent when data between animals were grouped together, electrical stimulation of adjacent areas in individual animals could produce different stepping patterns during locomotion. A somatotopic organization for individual muscles may also be present. The fact that some drug-induced locomotion trials showed the loss of phasic
A

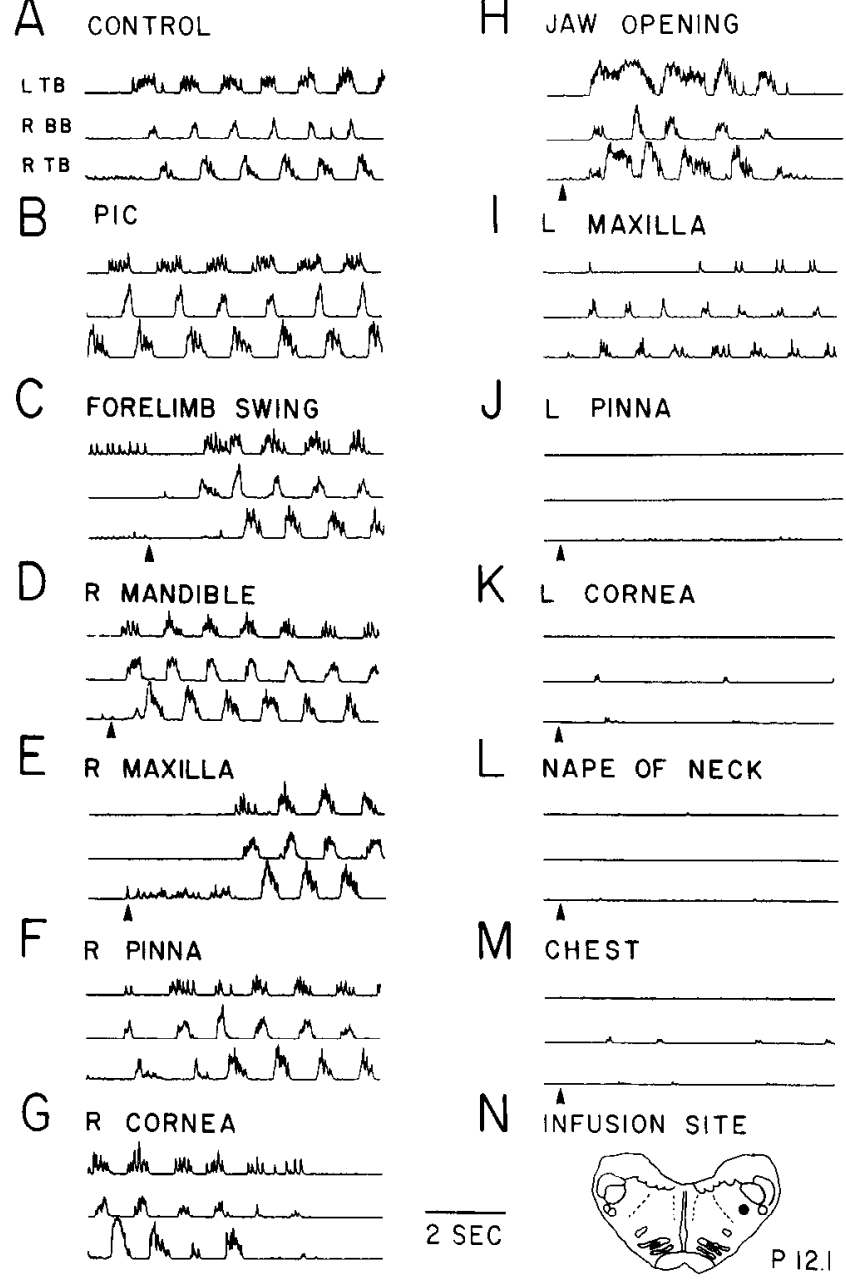

Figure 7. Picrotoxin infusion into the PLS facilitates locomotion produced by stimulation in the receptive field of the fifth nerve. $A$, Locomotion produced by electrical stimulation of the right PLS (P 12.1) in a site illustrated $N$ (filled circle). $B$, Spontaneous locomotion produced by injection of $15 \mathrm{nmol}$ (in $3 \mu \mathrm{l}, 0.005 \mathrm{M}$ ) PIC into this site, which could be iniliated $(C)$ by passive forelimb movement (swing) during periods of quiescence. $D-I$, Locomotion induced after PIC due to trigeminal receptive field stimulation (as indicated in each panel). Onset of stimulus indicated by the arrowheads. See text for details of onset latency for locomotion following the receptive field stimulation. Areas ineffective for the initiation of locomotion included the left pinna $(J)$, left cornea $(K)$, nape of neck $(L)$, and chest $(M) . N$ shows that electrical stimulation or PIC injection failed to produce any observable effects in a site located $1.5 \mathrm{~mm}$ lateral (open circle) to the site producing locomotion with PIC infusion (filled circle).

activity in specific muscle groups implies that the cell bodies which activate those muscle groups are outside of the infusion area and that their activity in the electrically induced locomotor trials was the result of activation of passing fibers. Similarly, recruitment of phasic EMG responses implics spread of the drug to cell bodies outside of the electrical stimulation site. Similar site-specific effects were observed by Ross and Sinnamon (1984) for electrical stimulation of the medulla in rats and by GarciaRill and Skinner (1987) in cats. A locomotor somatotopic organization within the MRF is supported by observations that some reticulospinal neurons only project to cervical spinal cord levels (Peterson et al., 1975) and that the firing patterns of reticulospinal cells may be linked to the activity of individual muscles from particular limbs during locomotion (Drew and 
Rossignol, 1984). Other factors such as the excitability levels of the brain stem and spinal cord may affect the ability of the brain stem to produce locomotion when stimulated (Mori et al., 1977, 1982). How this affects the recruitment of individual limbs or muscles during controlled locomotion is unclear.

Stimulation of the MRF by either electrical or chemical means produced postural changes prior to the onset of locomotion. Our data indicate that the postural changes occur in those monitored extensor muscles that are rhythmically active during electrically or drug-induced locomotion. For example, after infusion of GA into the MRF, an increase in EMG activity prior to stepping was found in the forelimb extensors which were rhythmically active during locomotion. In contrast, the hindlimb extensors were neither tonically nor phasically active after infusion of GA. Electrical stimulation of this area produced postural and locomotor activity in the hindlimb extensors, possibly by activation of the fibers of cells located more rostrally in the brain stem. This has been suggested to explain the effects of ventral tegmental field stimulation described by Mori and coworkers (1978, 1980), which produces increased hindlimb extensor activity and locomotion when electrically stimulated. Postural adjustments prior to the onset of locomotion have previously been reported during stimulation of the MIR (Mori et al., 1980; Garcia-Rill et al., 1985) and its reticular formation projection sites (Mori et al., 1978, 1980, 1982). Thus, while the MLR relays its descending command signal for locomotion, it may also influence parallel postural systems also located in the MRF. The degree of functional dependence or independence of these systems remains to be determined.

Although the present study was not intended to be an exhaustive neuropharmacological examination of the transmitters involved in the descending locomotor pathways, it does contribute to our understanding of them. It demonstrates that injection of GA into the MRF was effective in the production of locomotion. Infusion of either DL-HCA or PIC only produced decreases in the electrical threshold for the initiation of locomotion from these same sites. From these results we suggest that reticulospinal cells related to the production of locomotion possess receptors for excitatory amino acids and may be only partially under the control of a GABAergic inhibitory input. This is in agreement with iontophoretic studies on medial reticulospinal neurons (Têbecis, 1973; Greene and Carpenter, 1985). These results are somewhat different from those obtained with drug infusions into the MLR of cats, where PIC is effective in producing locomotion but GA is not (Garcia-Rill et al., 1985). However, infusions of GA into the MLR of intact rats have recently been reported to substantially increase the locomotor activity in the freely moving animal (Brudzynski et al., 1986).

The identity of the neurotransmitter released by the MLR at the MRF relay is still unknown. Garcia-Rill and Skinner (1987) suggest that a cholinergic and/or SP input from the MLR to the reticular formation may act to trigger locomotor events. However, recent studies using both the fictive (Noga et al., 1987) and treadmill locomotor preparations (B. R. Noga, S. J. Shefchyk, D. A. McCrea, and L. M. Jordan, unpublished observations) demonstrate that no significant alteration of the electrical threshold for MLR-evoked locomotion is seen following the intravenous administration of the ACh antagonists mecamylamine and atropine. The fact that few cells within the classical MLR contain SP (Léger et al., 1983) is also in contrast to this proposal. Thus, fibers from the MLR locomotor region contain other neurotransmitters that are involved in the transmission of the signal for initiation of locomotion through relays with the brain stem. The release of an excitatory amino acid at the MRF relay site may be inferred from the present results, but more evidence is needed confirm this.

\section{Pontomedullary locomotor strip}

The results from the present experiments support the idea that the area classically defined as the PLS (Mori et al., 1977; Shik and Yagodnitsyn, 1977) contains cell bodies that can produce locomotion with the appropriate chemical stimulus. The effective drug-induced locomotor sites are also located within the spinal nucleus of the trigeminal nerve. This is in disagreement with the proposal that the PLS contains only axons and that its cells of origin, the "pontomedullary locomotor column," are located even more ventral and medial to the PLS (Selionov and Shik, 1984). While we were able to produce locomotion by electrical stimulation within the "pontomedullary locomotor column," the lack of drug-induced locomotion in this region suggests that we were activating fibers of passage and not cell bodies involved in the generation of locomotion. With regard to the cells of origin of the PLS, we propose that they arc a collection of cells located in the spinal nucleus of the trigeminal nerve and in the immediately adjacent lateral reticular formation (LRF). Both anatomical and physiological evidence is available to support the idea that the LRF contains cells that are related to the trigeminal system. The LRF is contiguous dorsolaterally with the trigeminal spinal nucleus, and no obvious borders between them exist (Torvik, 1956). In addition, cells within and adjacent to the trigeminal nuclear complex (within the LRF) are activated by noxious and/or non-noxious stimulation of the trigeminal receptive field (Segundo et al., 1967; Nord and Kyler, 1968; Nord and Ross, 1973; Azerad et al., 1982) in a manner dependent upon stimulus intensity (Burton, 1968; Biedenbach, 1977). This activation is both mono- and polysynaptic (Nord and Kyler, 1968; Nord and Ross, 1973). This has led to the suggestion that the LRF cells are a ventromedial extension of (at least) the trigeminal subnucleus caudalis and that this system has an integral role in the mediation of facial pain at the bulbar level (Nord and Kyler, 1968; Nord and Ross, 1973).

The fact that PIC injection into the PLS region could make previously ineffective trigeminal field stimulation initiate treadmill locomotion indicates that the PLS region is closely related to the physiology of the spinal nucleus of the trigeminal nerve. Thus, it may be hypothesized that the PLS region contains a brain-stem system that provides a substrate for sensorimotor reflex initiation of locomotion. Stimulation of the pinna, which is innervated in part by the trigeminal nerve, sometimes elicits quadrupedal treadmill locomotion in the acute precollicularpostmamillary decerebrate cat (Aoki and Mori, 1981) and a characteristic "reflex posture" (Sherrington, 1906) resembling a part of locomotor movements. Since the area of the LRF may be involved in the integration of facial pain (see above), activity in this system may thus result in locomotor behavior as part of a generalized response to the appropriate stimulus applied in the facial or trigeminal peripheral field. In this context, it is suggested that this facial afferent initiation of locomotion is similar to initiation of locomotion by segmental afferents. For example, stepping movements may be elicited in cats by nociceptive stimuli applied to localized areas of the skin (Sherrington, 1910), including the perineal region (Afelt, 1970). Furthermore, stepping movements may also be initiated by dorsal 
root stimulation in mesencephalic (Budakova, 1972), chronic spinal, and in acute spinal cats pretreated with nialamide and DOPA (Grillner and Zangger, 1979). After injection of DOPA into acute spinal cats, stimulation of flexion reflex afferents (FRAs) also induces locomotorlike activity in spinal animals (Jankowska et al., 1967). Thus, facial and segmental afferent systems can produce locomotion when appropriately stimulated, and, in this context, the trigeminal and FRA system for the limbs may be considered analogous.

In decerebrate cats the adequate stimulus for eliciting locomotion applied to the pinn $!$ is pressure rather than touch (Aoki and Mori, 1981). However, in cats that have received a PIC injection into the PLS, gentle stroking of the trigeminal field may also evoke locomotion. This implies that the PLS region is normally under GABAergic inhibitory control. Removal of the GABAergic inhibition with an injection of PIC would produce a situation in which the afferent input would have a greater influence on the output activity of the cells in this region. This supposition is supported by the observation that pre- and postsynaptic inhibition in the trigeminal sensory nuclei is depressed by PIC (Nakamura and Wu, 1970; Ishimine et al., 1980). One may expect, therefore, that the production of locomotion by stimulation of various trigeminal receptive fields may be related to the somatotopic organization of the injected area in the brainstem. Although the somatotopic organization of the trigeminal area of the brain stem is complex (Nord and Kyler, 1968; Yokota and Nishikawa, 1980; Azerad et al., 1982), a differential effectiveness in producing locomotion by stimulation of the trigeminal receptive field was observed after injection of PIC into the PLS. The response characteristics described for the experiment illustrated in Figure 7 would correspond with an injection site predominantly located in the ipsilateral mandibular projection area of the LRF with diffusion spread partially including the maxillary and ophthalmic zones. Locomotion produced by contralateral trigeminal field stimuli may be due to a contralateral trigeminal nuclear projection (Nord and Kyler, 1968; Lovick and Wolstencroft, 1983).

The concept that the PLS and the trigeminal system are synonymous or closely related is strengthened by a number of other observations. Both the PLS (Shik and Yagodnitsyn, 1977) and the trigeminal sensory nuclei (Olszewski, 1950) have similar rostrocaudal distributions. In addition, the PLS originates from the medial MLR (Garcia-Rill et al., 1983), which includes the mesencephalic nucleus of the fifth nerve. Thus, locomotion produced by opening of the jaw after the injection of PIC into the PLS observed in this study may be the result of increased activity in the medullary projection of the mesencephalic nucleus (Corbin, 1942; Walberg et al., 1984). The fact that SP injection into the PLS produces locomotion also supports the idea of a close relationship between the PLS and trigeminal system. SP-containing trigeminal afferents have been shown to project to the spinal nucleus of the trigeminal nerve and the adjacent LRF (Cuello et al., 1978), where they may mediate the transmission of nociceptive and non-nociceptive information (Henry et al., 1977; Salt et al., 1983). In addition, a calcium-dependent release of SP in the trigeminal nuclei has been described (Jessell and Iversen, 1977).

Although activation of trigeminal cells in the lateral tegmentum may initiate locomotion after injection of PIC into the PLS region, the pathway by which it activates the spinal locomotor centers is unclear. The activity within the PLS is thought to propagate through the brain stem (Shik and Yagodnitsyn, 1978;

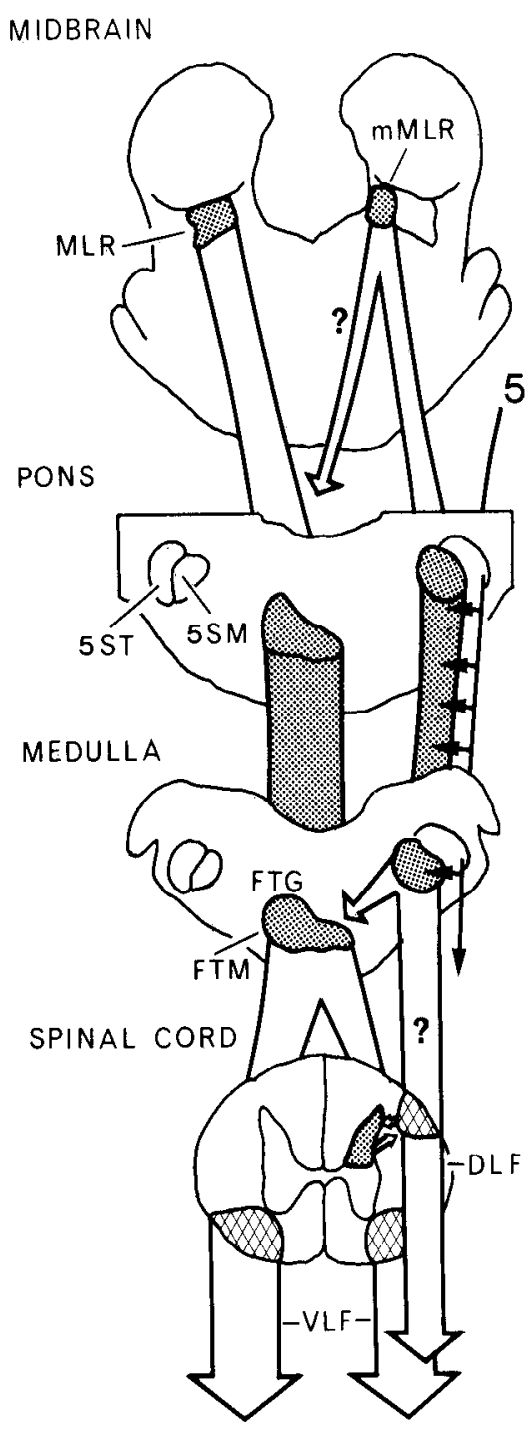

Figure 8. Organization of locomotor pathways descending from the midbrain to the spinal cord and their possible interrelationships (see text for details).

Selionov and Shik, 1984) to propriospinal neurons located in the dorsal horn of the cervical spinal cord (Kazennikov et al., $1983 \mathrm{~b}$ ). The axons of these propriospinal neurons descend through the spinal cord via the dorsolateral funiculus (Kazennikov et al., 1980, 1983a; Shik, 1983). It is possible that this brain stem-spinal cord pathway may be equivalent to the intranuclear trigeminospinal pathways described previously (Matsushita et al., 1981, 1982). Alternatively, the output of the PLS may relay, at least in part, through the MLR-reticulospinal pathway. This is supported by the observation that trigeminal field stimulation produced locomotion when GA was injected into the MRF. In addition, only electrical stimulation could produce locomotion in areas medial and ventral to PLS sites capable of producing locomotion when chemically activated. We suggest that electrical stimulation in this intermediate area was activating fibers projecting from the PLS to the MRF. This is supported by the observation that blocking synaptic transmission by reversible cooling of the MRF can abolish locomotion produced by electrical stimulation of this intermediate area (B. R. Noga, D. J. Kriellaars, and L. M. Jordan, unpublished observations). In addition, complete interruption of the PLS-DLF 
pathway with an extensive dorsal hemisection of the cervical spinal cord (C2-C3) does not abolish the ability to generate short bouts of locomotion with electrical stimulation of the PLS (B. R. Noga, D. J. Kriellaars, and L. M. Jordan, unpublished observations). MRF cells have becn shown to reccive trigeminal input (Lamarche et al., 1960). Furthermore, connections between the PLS and the MRF have been demonstrated electrophysiologically (Selionov and Shik, 1984). PLS stimulation has also been shown to facilitate locomotion produced by stimulation of the classical MLR (Mori et al., 1978).

The pathways in the mammalian brain stem involved in the production of locomotion in the decerebrate animal may be summarized in Figure 8. Briefly, the "classical MLR" relays its signal for the production of locomotion in the medial pontomedullary reticular formation (FTG, FTM). Reticulospinal cells (which may be somatotopically organized) then activate spinal centers for the generation of locomotion (at cervical and lumbar levels) via a pathway descending bilaterally in the VLF. This pathway is essential for the initiation of locomotion in intact animals since locomotion may still occur after transection of all areas of the spinal cord except the VLF (Eidelberg, 1981). The controlling elements activating this locomotor system and the transmitters released at the reticulospinal or spinal interneuronal levels are not fully understood. However, this study suggests that these reticulospinal cells may be partially under GABAergic control and that amino acid receptors may participate in the initiation of locomotion. Furthermore, the MRF may be activated by peripheral trigeminal stimuli. The PLS consists of trigeminal cells located in the lateral tegmentum and extends the length of the brain-stem trigeminal spinal nucleus, receiving inputs from the peripheral field of the trigeminal nerve (5), contralateral trigeminal sensory nuclei, and from the area of the mesencephalic nucleus or "medial MLR" (mMLR) (Garcia-Rill et al., 1983). The mMLR has also been shown to have a small projection to the MRF, but its contribution to the initiation of locomotion during stimulation of the mMLR remains to be elucidated. Results from this study suggest that the PLS system is under GABAergic control and may be activated by amino acids and SP to produce locomotion. The pathway(s) through which the PLS activates the spinal centers for locomotion remain unclear, but a relay via the MRF is suggested in the present paper. Alternatively, the PLS has been suggested to project in the spinal cord via the DLF as a polysynaptic propriospinal chain with the cells of origin located in the dorsal horns (Kazennikov et al., 1983a, b). The importance of this pathway to the production of locomotion by stimulation of the PI S remains to be determined.

\section{Appendix}

Abbreviations used in figures and text

5

$5 \mathrm{M}$

$5 \mathrm{P}$

$5 \mathrm{SM}$

$5 \mathrm{SP}$

$5 \mathrm{ST}$

7

$7 \mathrm{~L}$

$7 \mathrm{M}$

$\mathrm{CI}$

CP

FTG trigeminal nerve

motor trigeminal nucleus

principal sensory trigeminal nucleus

spinal trigeminal nucleus, magnocellular division spinal trigeminal nucleus, parvocellular division spinal trigeminal tract

facial nerve

facial nucleus, lateral division

facial nucleus, medial division

inferior central nucleus

cerebellar peduncle

gigantocellular tegmental field

$\begin{array}{ll}\text { FTL } & \text { lateral tegmental field } \\ \text { FTM } & \text { magnocellular tegmental field } \\ \text { IC } & \text { inferior colliculus } \\ \text { IFT } & \text { infratrigeminal nucleus } \\ \text { IOM } & \text { medial accessory nucleus of the inferior olive } \\ \text { KF } & \text { Kölliker-Fuse nucleus } \\ \text { LRI } & \text { lateral reticular nucleus, internal division } \\ \text { P } & \text { pyramidal tract } \\ \text { PPR } & \text { postpyramidal nucleus of the pyramidal tract } \\ \text { PR } & \text { paramedian reticular nucleus } \\ \text { SOL } & \text { lateral nucleus of the superior olive } \\ \text { SOM } & \text { medial nucleus of the superior olive } \\ \text { TB } & \text { trapezoid body }\end{array}$

\section{References}

Afelt, Z. (1970) Reflex activity in chronic spinal cats. Acta Neurobiol. Exp. 30: 129-144.

Aoki, M., and S. Mori (1981) Locomotion elicited by pinna stimulation in the acute precollicular-post-mammillary decerebrate cat. Brain Res. 214: 424-128.

Azerad, J., A. Woda, and D. Able-Fessard (1982) Physiological properties of neurons in different parts of the cat trigeminal sensory complex. Brain Res. 246: 7-21.

Berman, A. L. (1968) The Brain Stem of the Cat, University of Wisconsin Press, Madison.

Biedenbach, M. A. (1977) Response of trigeminal neurons in pars interpolaris to non-noxious and noxious stimulation. In Pain in the Trigeminal Region, D. J. Anderson and B. Matthews, eds., pp. 233244, Elsevier, Amsterdam.

Brudzynski, S. M., P. E. Houghton, R. D. Brownlee, and G. J. Mogenson (1986) Involvement of neuronal cell hodies of the mesencephalic locomotor region in the initiation of locomotor activity of freely behaving rats. Brain Res. 16: 377-381.

Budakova, N. N. (1972) Stepping movements evoked by repetitive dorsal root stimulation in a mesencephalic cat. Neurosci. Behav. Physiol. 5: 355-363.

Burton, H. (1968) Somatic sensory properties of caudal bulbar reticular neurons in the cat (Felis domestica). Brain Res. 11: 357-372.

Corbin, K. B. (1942). Probst's tract in the cat. J. Comp. Neurol. 77: $455-467$.

Cuello, A. C., M. DelFiacco, and G. Paxinos (1978) The central and peripheral ends of the substance P-containing sensory neurones in the rat trigeminal system. Brain Res. 152: 499-509.

Drew, T., and S. Rossignol (1984) Phase-dependent responses evoked in limb muscles by stimulation of medullary reticular formation during locomotion in thalamic cats. J. Neurophysiol. 52: 653-675.

Eidelberg, E. (1981) Consequences of spinal cord lesions upon motor function, with special reference to locomotor activity. Prog. Neurobiol. 17: 185--202.

Garcia-Rill, E., and R. D. Skinner (1987) The mesencephalic locomotor region. I. Activation of a medullary projection site. Brain Res. 411: $1-12$.

Garcia-Rill, E., R. D. Skinner, S. A. Gilmore, and R. Owings (1983) Connections of the mesencephalic locomotor region (MLR). II. Afferents and efferents. Brain Res. Bull. 10:63-71.

Garcia-Rill, E., R. D. Skinner, and J. A. Fitzgerald (1985) Chemical activation of the mesencephalic locomotor region. Brain Res. 330: 43-54.

Goodchild, A. K., R. A. L. Dampney, and R. Bandler (1982) A method for evoking physiological responses by stimulation of cell bodies, but not axons of passage, within localized regions of the central nervous system. J. Neuroscience Methods 6: 351-363.

Greene, R. W., and D. O. Carpenter (1985) Actions of neurotransmitters on pontine medial reticular formation neurons of the cat. $\mathrm{J}$. Neurophysiol. 54: 520-531.

Grillner, S., and P. Zangger (1979) On the central generation of locomotion in the low spinal cat. Exp. Brain Res. 34: 241-261.

Henry, J. L., J. W. Hu, G. E. Lucier, and B. J. Sessle (1977) Responses of units in the trigeminal sensory nuclei to oral-facial stimuli and to substance P. In Pain in the Trigeminal Region, D. J. Anderson and B. Matthews, eds., pp. 295-306, Elsevier, Amsterdam.

Ingram, W. R., S. W. Ranson, F. I. Hannett, F. R. Zeiss, and E. H. 
Terwilliger (1932) Results of stimulation of the tegmentum with the Horsley-Clarke stereotaxic apparatus. Arch. Neurol. Psychiatry 28. 513-541.

Ishimine, S., O. Hikosaka, and Y. Nakamura (1980) Spatio-temporal patterns of pre- and postsynaptic inhibition induced by primary afferent activation in the trigeminal sensory nucleus in cats. Exp. Brain Res. 40: 154-163.

Jankowska, E., M. G. M. Jukes, S. Lund, and A. Lundberg (1967) The effect of DOPA on the spinal cord. VI. Half-centre organization of interneurones transmitting effects from the flexor reflex afferents. Acta Physiol. Scand. 70: 389-402.

Jessell, T. M., and L. L. Iversen (1977) Opiate analgesics inhibit substance $P$ release from rat trigeminal nucleus. Nature 268: 549-551.

Jordan, L. M. (1986) Initiation of locomotion from the mammalian brainstem. In Neurobiology of Vertebrate Locomotion, S. Grillner, P. S. G. Stein, D. G. Stuart, H. Forssberg, and R. M. Herman, eds., pp. 21-37, Macmillan, London

Kazennikov, O. V., M. L. Shik, and G. V. Yakovleva (1980) Two pathways for the brainstem "locomotor influence" on the spinal cord. Fiziol. Zh. (SSSR) 66: 1260-1263.

Kazennikov, O. V., M. L. Shik, and G. V. Yakovleva (1983a) Stepping movements induced in cats by stimulation of the dorsolateral funiculus of the spinal cord. Bull. Exp. Biol. Med. 96: 1036-1039.

Kazennikov, O. V., M. L. Shik, and G. V. Yakovleva (1983b) Responses of upper cervical spinal neurons in cats to stimulation of the brain-stem locomotor region at different frequencies. Neurophysiology 15: 256-261.

Kettler, J., and L. M. Jordan (1984) Metabolic mapping of the brainstem during fictive locomotion. Soc. Neurosci. Abstr. 10:633.

Klüver, H., and E. Barrera (1953) A method for the combined staining of cells and fibres in the nervous system. J. Neuropathol. Exp. Neurol. 12: 400-403.

Lamarche, G., J. M. Langlois, and M. Heon (1960) Unit study of the trigeminal projections in the reticular formation of the medulla oblongata in the cat. Can. J. Biochem. Physiol. 38: 1163-1166.

Lee, H. J., D. B. Rye, and B. H. Wainer (1986) Combined retrogradeimmunohistochemical evidence that the pediculopontine tegmental nucleus does not project to extrapyramidal motor structures. Soc. Neurosci. Abstr. 12: 1546

Léger, L., Y. Charnay, J. A. Chayvialle, A. Bérod, F. Dray, J. F. Pujol, M. Jouvet, and P. M. Dubois (1983) Localization of substance P and enkephalin-like immunoreactivity in relation to catecholaminecontaining cell bodies in the cat dorsolateral pontine tegmentum: An immunofluorescence study. Neuroscience $8: 525-546$.

Lovick, T. A, and J. H. Wolstencroft (1983) Projections from brain stem nuclei to the spinal trigeminal nucleus in the cat. Neuroscience 9: $411-420$

Matsushita, M., N. Okado, M. Ikeda, and Y. Hosoya (1981) Descending projections from the spinal and mesencephalic nuclei of the trigeminal nerve to the spinal cord in the cat. A study with the horseradish peroxidase technique. J. Comp. Neurol. 196: 173-187.

Matsushita, M., M. Ikeda, and N. Okado (1982) The cells of origin of the trigeminothalamic, trigeminospinal, and trigeminocerebellar projections in the cat. Neuroscience $7: 1439-1454$.

Mori, S., M. L. Shik, and A. S. Yagodnitsyn (1977) Role of pontine tegmentum for locomotor control in mesencephalic cat. J. Neurophysiol. 40: 284-295.

Mori, S., H. Nishimura, C. Kurakami, T. Yamamura, and M. Aoki (1978) Controlled locomotion in the mesencephalic cat: Distribution of facilitatory and inhibitory regions within pontine tegmentum. J. Neurophysiol. 41: 1580-1591.

Mori, S., H. Nishimura, and M. Aoki (1980) Brain stem activation of the spinal stepping generator. In Reticular Formation Revisited (IBRO Monogr. Ser. Vol. 6), J. A. Hobson and M. A. B. Brazier, eds., pp. 241-259, Raven, New York.

Mori, S., K. Kawahara, T. Sakamoto, M. Aoki, and T. Tomiyama (1982) Setting and resetting of level of postural muscle tone in decerebrate cat by stimulation of brain stem. J. Neurophysiol. 48: 737-748.

Nakamura, Y., and C. Y. Wu (1970) Presynaptic inhibition of jawopening reflex by high-threshold afferents from the masseter muscle of the cat. Brain Res. 23: 193-211.

Noga, B. R., J. Kettler, and L. M. Jordan (1984) Chemical excitation of cells in the pons and medulla produces locomotion in decerebrate cats. Soc. Neurosci. Abstr. 10:632.
Noga, B. R., D. J. Kriellaars, R. M. Brownstone, B. Mallory, and L. M. Jordan (1986) A common pathway for MLR evoked PSPs and the initiation of locomotion. Soc. Neurosci. Abstr. 12: 877.

Noga, B. R., S. J. Shefchyk, J. Jamal, and L. M. Jordan (1987) The role of Renshaw cells in locomotion: Antagonism of their excitation from motor axon collaterals with intravenous mecamylamine. Exp. Brain Res. 66: 99-105.

Nord, S. G., and H. J. Kyler (1968) A single unit analysis of trigeminal projections to bulbar reticular nuclei of the rat. J. Comp. Neurol. 134: $485-499$.

Nord, S. G., and G. S. Ross (1973) Responses of trigeminal units in the monkey bulbar lateral reticular formation to noxious and nonnoxious stimulation of the face: Experimental and theoretical considerations. Brain Res. 58: 385-399.

Olszewski, J. (1950) On anatomical and functional organization of spinal trigeminal nucleus. J. Comp. Neurol. 92: 401-413.

Orlovsky, G. N. (1970) Connexions of the reticulo-spinal neurones with the "locomotor sections" of the brainstem. Biophysics 15: 178186.

Peterson, B. W., R. A. Maunz, N. G. Pitts, and R. G. Mackel (1975) Patterns of projection and branching of reticulospinal neurons. Exp. Brain Res. 23: 333-351.

Peterson, B. W., N. G. Pitts, and K. Fukushima (1979) Reticulospinal connections with limb and axial motoneurons. Exp. Brain Res. 36: $1-20$.

Ross, G. S., and H. M. Sinnamon (1984) Forelimb and hindlimb stepping by the anesthetized rat elicited by electrical stimulation of the pons and medulla. Physiol. Behav. 33: 201-208.

Salt, T. E., R. Morris, and R. G. Hill (1983) Distribution of substance $\mathrm{P}$-responsive and nociceptive neurones in relation to substance P-immunoreactivity within the caudal trigeminal nucleus of the rat. Brain Res. 273: 217-228.

Segundo, J. P., T. Takenaka, and H. Encabo (1967) Somatic sensory propertics of bulbar reticular ncurons. J. Ncurophysiol. 30: 12211238 .

Selionov, V. A, and M. L. Shik (1984) Medullary locomotor strip and column in the cat. Neuroscience 13: 1267-1278.

Shefchyk, S.J., and L. M. Jordan (1985) Excitatory and inhibitory postsynaptic potentials in alpha-motoneurons produced during fictive locomotion by stimulation of the mesencephalic locomotor region. J. Neurophysiol. 53: 1345-1355.

Shefchyk, S. J., R. M. Jell, and L. M. Jordan (1984) Reversible cooling of the brainstem reveals areas required for mesencephalic locomotor region evoked treadmill locomotion. Exp. Brain Res. 56: 257-262.

Sherrington, C. S. (1906) The Integrative Action of the Nervous System, Yale University Press, New Haven, CT.

Sherrington, C. S. (1910) Flexion-reflex of the limb, crossed extension reflex, and reflex stcpping and standing. J. Physiol. (Lond.) 40: 28121.

Shik, M.L. (1983) Action of the brainstem locomotor region on spinal stepping generators via propriospinal pathways. In Spinal Cord Reconstruction, C. C. Kao, R. P. Bunge, and P. J. Reier, eds., pp. 421434, Raven, New York.

Shik, M. L., and A. S. Yagodnitsyn (1977) The pontobulbar "locomotor strip." Neurophysiology 9: 72-74

Shik, M. L., and A. S. Yagodnitsyn (1978) Unit responses in the "locomotor strip" of the cat hindbrain to microstimulation. Neurophysiology 10: 373-379.

Shik, M. L., F. V. Severin, and G. N. Orlovsky (1967) Structures of the brain stem responsible for evoked locomotion. Fiziol. Zh. (SSSR) 53: $1125-1132$.

Steeves, J. D., and L. M. Jordan (1980) Localization of a descending pathway in the spinal cord which is necessary for controlled treadmill locomotion. Neurosci. Lett. 20: 283-288.

Steeves, J. D., and L. M. Jordan (1984) Autoradiographic demonstration of the projections from the mesencephalic locomotor region. Brain Res. 307: 263-276.

Tēbecis, A. K. (1973) Transmitters and reticulospinal neurons. Exp Neurol. 40:297-308

Torvik, A (1956) Afferent connections to the sensory trigeminal nuclei, the nucleus of the solitary tract and adjacent structures. J. Comp. Neurol. 106: 51-141.

Walberg, F., E. Dietrichs, and T. Norby (1984) The medullary projection from the mesencephalic trigeminal nucleus. An experimental 
study with comments on the intrinsic trigeminal interconnections. Exp. Brain Res. 56: 377-383.

Yokota, T., and N. Nishikawa (1980) Reappraisal of somatotopic tactile representation within trigeminal subnucleus caudalis. J. Neurophysiol. 43: 700-712.
Zelman, F. P., L.-M. Kow, and D. W. Pfaff (1983) Effect of interruption of bulbospinal pathways on lordosis, posture, and locomotion. Exp. Neurol. 81: 177-194. 